九州大学学術情報リポジトリ

Kyushu University Institutional Repository

\title{
Profiling and Technical Evaluation of Existing Agricultural Warehouses in the Agusan Provinces, Caraga Region, Philippines
}

Engr. Philip Donald C. Sanchez

Department of Agricultural and Biosystems Engineering, College of Engineering and Geosciences, Caraga State University

Kimberly S. Amar

Department of Agricultural and Biosystems Engineering, College of Engineering and Geosciences, Caraga State University

Melody E. Rayoso

Department of Agricultural and Biosystems Engineering, College of Engineering and Geosciences, Caraga State University

https://doi.org/10.5109/4738578

出版情報: Proceedings of International Exchange and Innovation Conference on Engineering \& Sciences (IEICES). 7, pp. 129-135，2021-10-21. 九州大学大学院総合理工学府 バージョン:

権利関係 : 


\title{
Profiling and Technical Evaluation of Existing Agricultural Warehouses in the Agusan Provinces, Caraga Region, Philippines
}

\author{
Engr. Philip Donald C. Sanchez ${ }^{1,2^{*}}$, Kimberly S. Amar ${ }^{1}$, Melody E. Rayoso ${ }^{1}$ \\ ${ }^{1}$ Department of Agricultural and Biosystems Engineering, College of Engineering and Geosciences, Caraga State \\ University, Butuan City 8600, Philippines \\ ${ }^{2}$ Center for Resource Assessment, Analytics and Emerging Technologies (CReATE), Caraga State University, \\ Ampayon, Butuan City 8600, Philippines \\ *Corresponding author email: pcsanchez@carsu.edu.ph
}

\begin{abstract}
In this work, profiling and technical evaluation of existing agricultural warehouses in the Agusan Provinces of Caraga Region, Philippines was conducted. The study focused mainly on assessing the suitability of the warehouses in terms of technical and structural requirements based on the Philippine Agricultural Engineering Standards (PAES). This undertaking is vital to expedite farmers' time and effort in identifying the nearest available agricultural warehouses to store goods after harvesting or prior to processing. For this purpose, simple random sampling survey was conducted using the developed survey questionnaires categorized in to the suitability and functionality parameters. Results of the study showed that more than $90 \%$ of the existing agricultural warehouses have conformed to the structural requirements stated in the PAES. However, study also revealed that only $42 \%$ of the surveyed warehouses did not adhere with the functional requirements outlined in the PAES. Hence, suitability and functionality of the warehouses were assessed.
\end{abstract}

Keywords: Agricultural Warehouses; Agricultural Engineering Standards; Functionality; Suitability .

\section{INTRODUCTION}

The Philippines is primarily an agricultural country, with a land area of 299,762 square kilometers and a population of 70 million people [5]. Eighty percent (80\%) and twenty percent $(20 \%)$ of the population consumes rice and corn respectively. However, as projected, the country has been insufficient in its staple food requirements for nearly two decades [5]. Every year, five to ten percent of the staple food requirements are mainly imported. Meanwhile, the postharvest losses in rice and corn amount to $15 \%$ and $13 \%$, respectively.

According to the Philippine Department of Agriculture (DA) in 2001, high-value crops contributed significantly (around 57 percent) to the country's total agricultural productivity [6]. In order to develop its agriculture, the country adopts improved technologies for both production and post-production operations: Some of the priorities in the development of the postharvest sector are research and development, training, extension, and commercialization of postharvest technologies, postharvest facility assistance through soft loan credit to farmers' organizations/ cooperatives [5].

Warehouses are used to store and protect items from the elements. In other words, warehousing is the process of storing or maintaining large amounts of products from the time they are purchased or manufactured until they are used or sold. After harvesting of agricultural food items, it exhibit respiration, transpiration, and ripening process [16]. If not managed, this can cause to quality deterioration and losses. Therefore, storing in a warehouse is desirable to retain quality and safety of horticultural products and refrain market price problems. Generally, $10-20 \%$ of the market price can be enhanced during off-season, which is advantageous for the farmers due to storage [8].
Just like any other infrastructures, agricultural structures particularly warehouses need quality assessment as it plays vital role in securing safe, zero-energy building and decent for animals and foods [17].

Agricultural warehouses in the provinces of Agusan del Norte and Agusan del Sur are not that many and the farmers find it difficult to find the nearest agricultural warehouse that is suitable for their products. In addition, most farmers in the provinces of

Agusan are not educated on the availability of services provided by the active warehouses. There is also no database or record on the functional and technical capacities of the existing warehouses. Thus, the present work wishes to study and assess the technical and functional status of the existing warehouses in the provinces of Agusan. This research endeavor will be of great impact for the farmers and food suppliers to have available background/data on the availability, location, and accessibility of the existing warehouses.

\section{Methodology}

\subsection{Study Area}

The study was conducted in the province of Agusan del Norte and Agusan del Sur with total land area of 273 thousand hectares and 999 thousand hectares, respectively.

\subsection{Process Flow}

To attain the required information aimed by this study, a process flow was made to properly guide the step-bystep process of this study (Figure 1). During the first phase of the study, a survey questionnaire was drafted through a series of consultations from the adviser followed by the finalization of the draft that covers the basic information of the warehouse, profile, structural 
and functional information. A field survey was later conducted then validation and interview of the existing agricultural warehouses. After which, data analysis and interpretation were carried out through descriptive statistics and basic mathematical computation such as the percentage and frequency distribution.

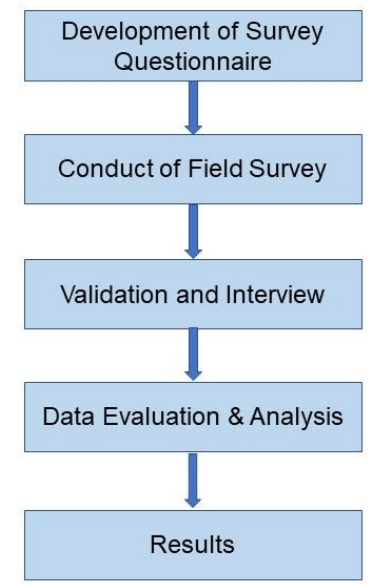

Figure 1. Procedural Flow of the Study.

\subsection{Research Design}

Research design is the blueprint for fulfilling research objectives and answering research questions [2]. In other words, it is a master plan specifying the methods and procedures for collecting and analyzing the needed information. It ensures that the study will be relevant to the problem and that it uses economical procedures.

This particular study adopted a simple random sampling survey design to address the study's questions and purposes. This was used to collect information from the respondents by use of questionnaires. The finding and conclusion of the study depends on the utilization of statistical data collection and analysis.

\subsection{Sampling Technique}

\subsubsection{Target Population}

Existing agricultural warehouses in the provinces of Agusan that were selected through simple random sampling were taken to constitute the study's sample size. This is on the basis of the suggestion that if the study of the entire population is impossible, sampling is appropriate to ensure that the sample group is a true representative of the population and to obtain unbiased results.

However, due to the situation in the study area brought by the pandemic, there were only 19 sampled warehouses interviewed. Travel restrictions and regulations under Modified Enhanced Community Quarantine (MECQ) were strictly implemented that other warehouses refused to conduct interviews and the like.

\subsubsection{Unit Analysis and Respondents}

As far as the unit of analysis is concerned, the existing warehouses were chosen as the unit of analysis for this study. And every warehouse representative was the pertinent respondent for the study. Warehouse focal person/head was chosen because of the fact that they are most accustomed with and have the relevant information pertaining to the warehouse activities.

\subsubsection{Data Collection and Data Gathering Tools}

The study data were analyzed using Statistical Package for the Social Science (SPSS). Frequency tables and percentages were used to summarize the demographic information of respondents, scores on all the dimensions were assessed in order to address the study's objectives. Finally, detailed interpretation and discussion of the results of the statistical analysis was provided.

Primary source of data/information was used for the purpose of conducting this particular research. Primary data is the information that the researcher finds out by himself/herself regarding a specific topic having the likely advantage that the data is collected with the research's purpose in mind, whereby ensuring the resulting consistency of the information with the research questions and purpose [14].

The primary data was gathered through a developed questionnaire from the entire population of the warehouses. The questionnaire was designed in a way that enabled to capture the demographic information of respondents and the evaluation of the warehouse.

\subsection{Assessment of Existing Agricultural Warehouses}

The researchers assessed the existing agricultural warehouses in the provinces of Agusan to determine why some agricultural warehouses continue its service and why others have stopped working. To be able to assist farmers in addressing their common issue of storing goods to the government, the existing agricultural warehouses were assessed based on the following: (a) Suitability (b) Functionality.

\subsubsection{Suitability}

The suitability of the existing agricultural warehouses was also assessed to determine how suitable the warehouse is based on its location. Choosing the suitable location can make all the difference in how effective, efficient, and profitable a warehouse is. The location of the warehouse shall be in accordance with the Philippine Agricultural Engineering Standards (PAES 419:2015). Agricultural Structures Warehouse for Bagged Storage of Grains. 


\subsubsection{Functionality}

Assessment on the warehouse's functionality was undertaken to determine if implementation of identified warehouses was carried out as planned and to know the reason behind of why the warehouse have ceased operation.

\subsection{Requirements for Service}

In order for agricultural product storage building to render its greatest value to the user, it must be serviceable. The floor plan of a warehouse shall be based on the Philippine Agricultural Engineering Standards (PAES 419:2015). Agricultural Structures - Warehouse for Bagged Storage of Grains.

\subsubsection{Structural}

The structural is the most important in constructing a warehouse. The construction of the foundation and floor shall conform to the Philippine Agricultural Engineering Standards (PAES 419:2015) and the floor should be strong and capable to carry heavy loads and vibrations. Walls, roofs, doors, ventilation, and other structural involved in the construction of agricultural warehouses should be based on Philippine Agricultural Engineering Standards (PAES 419:2015) Agricultural Structures - Warehouse for Bagged Storage of Grains.

\section{Results \& Discussions}

\subsection{Data}

Nineteen (19) warehouses as a sample size was identified. During the data gathering, all nineteen (19) identified respondents were taken from different municipalities in the provinces of Agusan and were surveyed thoroughly.

\subsection{Validation of Points}

Global Positioning System (GPS) was used to obtain geographical coordinates, which were then used to plot the validated points collected during the field survey as displayed in Figure 2.

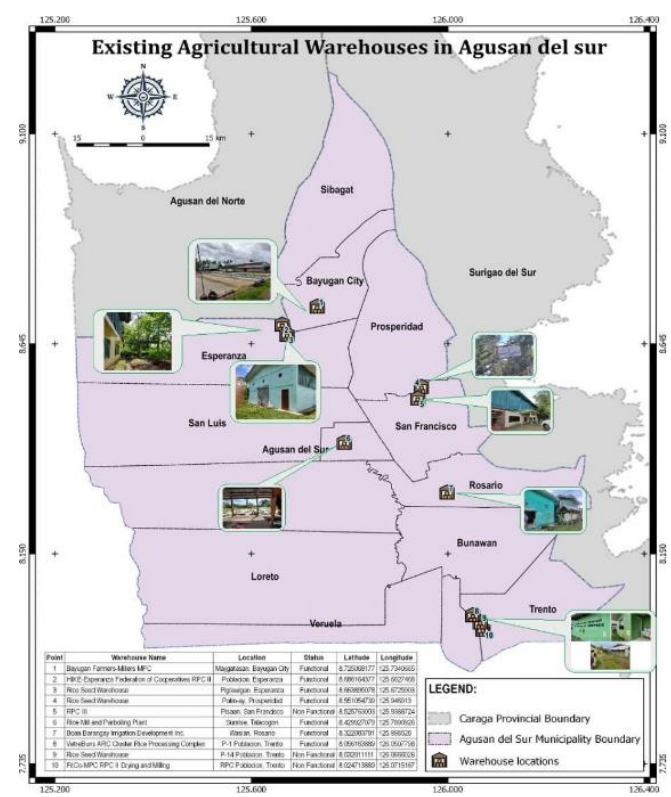

Figure 2. Validated points of Existing Agricultural warehouses in the province of Agusan del Sur

\subsection{Location, Organization, and Inventory of Existing Agricultural Warehouses}

The first section of the questionnaire sought to identify the warehouse locations. It enabled the researcher to validate the existence of the agricultural warehouses. The responses are summarized in the table 1 above, which consists of a maximum of 19 responses. The data on the list of existing agricultural warehouses was obtained from the Department of Agriculture Regional Field Office and Provincial Office.

Based on the data as shown in Table 1, there were 19 agricultural warehouses accounted for in the entire provinces of Agusan. As to the province of Agusan del Norte, Butuan City has the highest number of sampled warehouses gaining a count of six (6), while the other municipalities have only one (1). On the other hand, the province of Agusan del Sur has a total of ten (10) sampled warehouses. These warehouses came from 7 municipalities wherein Trento has the highest number of sampled warehouses gaining a count of three, Esperanza has two while the other municipalities have only one. The results were acquired through an actual field validation surveyed. 


\begin{tabular}{|c|c|c|c|}
\hline PROVINCE & MUNIC IP ALITY & FREQUENCY & PERCENTAGE \\
\hline \multirow[t]{4}{*}{ Agusan Del Norte } & Butuan City & 6 & $31.58 \%$ \\
\hline & Cabadbaran City & 1 & $5.26 \%$ \\
\hline & Kitcharao & 1 & $5.26 \%$ \\
\hline & $\begin{array}{l}\text { Remedios T. Romualdez } \\
\text { (RTR) }\end{array}$ & 1 & $5.26 \%$ \\
\hline \multirow[t]{7}{*}{ Agusan Del Sur } & Bayugan City & 1 & $5.26 \%$ \\
\hline & Esperanza & 2 & $10.53 \%$ \\
\hline & Prosperidad & 1 & $5.26 \%$ \\
\hline & Rosario & 1 & $5.26 \%$ \\
\hline & San Francisco & 1 & $5.26 \%$ \\
\hline & Talacogon & 1 & $5.26 \%$ \\
\hline & Trento & 3 & $15.78 \%$ \\
\hline
\end{tabular}

Moreover, the study also aimed at conducting an inventory in the existing agricultural warehouses including the available machinery and equipment. Among the advantages of available machineries include: (1) machines are fundamental in the sustainability of warehouses to increase the power supply in the operation resulting to more tasks can be completed at the right time, (2) additional income generation for the organization, and (3) machineries/technologies also help in saving the cost of labor.

\subsection{Respondent's Demographic Profile}

Data gathered through the questionnaire was subjected to frequency counts. In other words, the responses for each individual question were added together to find the highest frequency occurrence (i.e. the number of times that a particular response occurs). These responses to the questions, which are quantified, are then presented in percentage forms. This analysis is presented in tabular form. The researcher uses tables containing a variable.

Based on the results, $73.68 \%$ of the respondents were male while $26.32 \%$ were female from a total of 10 identified respondents.

\subsubsection{Government Funds/Supported Warehouses}

Among the 19 identified warehouses, only one warehouse, is not duly supported by the Department of Agriculture (DA). The remaining one warehouse is a convergent project of the DAR and Municipal Agriculture Office. This only shows that $94.74 \%$ of the warehouses are funded by the government thus DA.

\subsubsection{Total Number of Members}

As presented in Table 2, the distribution of members for the entire sample size is accounted. The figures showed that in a total of 3,819 members of the warehouse from both of the provinces, 1,669 were males while 2, 150 were females. This also shows that there are more female members than male members in a warehouse.

Table 2. Distribution of Members According to Gender.

\begin{tabular}{lc}
\hline Gender & Total \\
\hline Male & 1,669 \\
Female & 2,150 \\
Total & 3,819 \\
\hline
\end{tabular}

\subsection{Basic Information of the Existing Agricultural Warehouses}

In the second part of the questionnaire, questions such as classification of the customers, storage modality, and commodities stored, services offered as well as the condition of the warehouse were assessed.

\subsubsection{Customers of Existing Agricultural Warehouses}

For the first question as tabulated in Table 3, the survey questionnaire particularly on the classification of farmers or type of customer they belonged was facilitated/questioned. Based on the results, 7 out of 19 warehouses are consumed solely by the farmers and one warehouse is solely consumed by the National Food Authority. It also shows that three warehouses are consumed jointly either by a farmer and NFA or Farmer and Retailer and/or Farmer, Retailer, Wholesaler, and DA. This only implied that farmers really had the high benefits. 
Table 3. Classification of Type of Customer in a Warehouse.

\begin{tabular}{lcc}
\hline Customers & Frequency & Percentage \\
\hline Farmer & 7 & $36.84 \%$ \\
Farmer \& Retailer & 9 & $47.37 \%$ \\
$\begin{array}{l}\text { Farmer, Retailer \& } \\
\text { wholesaler }\end{array}$ & 2 & $10.53 \%$ \\
NFA & 1 & $5.26 \%$ \\
Farmer and NFA & 1 & $5.26 \%$ \\
Farmer, Retailer \& & 1 & $5.26 \%$ \\
DA & &
\end{tabular}

\subsubsection{Storage Fee of Existing Agricultural Warehouses}

Respondents were asked to indicate the classification of storage in the warehouse. The resulting responses have been classified into four (4): $/ \mathrm{kg}$, /bag, /package, and not applicable.

Table 4. Storage Classification/Modality.

\begin{tabular}{lll}
\hline Storage & Frequency & Percentage \\
Classification & & \\
\hline$/ \mathrm{kg}$ & 3 & $15.78 \%$ \\
$/ \mathrm{bag}$ & 12 & $63.16 \%$ \\
$/$ Package & 0 & $0.00 \%$ \\
$\begin{array}{l}\text { Not } \\
\text { applicable }\end{array}$ & 4 & $21.05 \%$
\end{tabular}

It can be inferred from Table 4 that the most preferred way of payment in the warehouses was the by bag payment with the percentage of $63.16 \%$ and only $15.78 \%$ paid by kilogram. The remaining $21.05 \%$ is for the warehouse that was temporarily not functional. During the interviewed with the respondents, it is said that the member of the said warehouses has the privileged to ask for more discount in renting fees.

\subsubsection{Commodities Stored in Existing Agricultural Warehouses}

Table 5 shows the distribution of agricultural commodities stored in the agricultural warehouses which the respondents were asked to indicate. Results have shown $57.89 \%$ of the commodities stored in a warehouse were Rice and Paddy. Next to it is the paddy alone with a $21.05 \%$ corresponding part of a whole. In addition, Maize and Paddy covers $10.53 \%$ only and Maize, Rice, and Paddy got the lowest percentage with $5.26 \%$.
Table 5. Distribution of Agricultural Commodities Stored.

\begin{tabular}{lcc}
\hline Commodities & Frequency & Percentage \\
Stored & 4 & $21.05 \%$ \\
\hline Paddy & 11 & $57.89 \%$ \\
Rice \& Paddy & 1 & $5.26 \%$ \\
Rice \& Maize & 2 & $10.53 \%$ \\
Maize \& Paddy & 1 & $5.26 \%$ \\
$\begin{array}{l}\text { Maize, Rice } \\
\text { Paddy }\end{array}$ & &
\end{tabular}

\subsubsection{Services Offered in Existing Agricultural Warehouses}

It can be seen in Table 6 the percentages and frequency count of services offered in the existing agricultural warehouses from both provinces. Result shows that most of the agricultural warehouses are maximized for drying, processing, and milling with the percentage of $78.95 \%$ and the remaining percent serves as a storage only.

Table 6. Services Offered.

\begin{tabular}{lcc}
\hline \multicolumn{1}{c}{ Services Offered } & Frequency & Percentage \\
\hline Storage & 4 & $21.05 \%$ \\
Drying, Processing & 15 & $78.95 \%$ \\
and Milling & & \\
\hline
\end{tabular}

\subsection{Functionality of the Existing Agricultural Warehouses}

The respondents were asked to indicate whether the warehouse is still operating or not. As shown in Table 7 , most of the surveyed warehouses were functional. It also appears that $78.95 \%$ of the existing warehouses were still operating and $21.05 \%$ have ceased operation. This question was asked to assess the functionality of the existing agricultural warehouses. Based on the survey, most common problem found behind the warehouses that have ceased operation were commonly structural related and the lack of equipment wherein they cannot compete in the market.

Table 7. Condition of the Warehouse.

\begin{tabular}{lcc}
\hline \multicolumn{1}{c}{ Condition } & Frequency & Percentage \\
\hline Functional & 15 & $78.95 \%$ \\
Non-functional & 4 & $21.05 \%$
\end{tabular}




\subsection{Suitability of the Existing Agricultural Warehouse}

The location of the warehouses was also checked to assess its suitability. Based on the results (Table 8), all existing agricultural warehouses were suitable which has a great impact on the warehouse success.

Table 8. Suitability of Warehouses based on its Location

\begin{tabular}{cccc}
\hline Location & $\begin{array}{c}\text { Responses } \\
\text { (Y/N) }\end{array}$ & Frequency & Percent \\
\hline $\begin{array}{c}\text { Accessible } \\
\text { to all forms } \\
\text { of transport } \\
\text { system }\end{array}$ & Yes & 19 & $100 \%$ \\
$\begin{array}{c}\text { Not located } \\
\text { near busy } \\
\text { public }\end{array}$ & Yes & 15 & $78.95 \%$ \\
Free from & No & 9 & $21.05 \%$ \\
fire hazard & Yes & 17 & $89.47 \%$ \\
\hline
\end{tabular}

\subsection{Structural Requirements of Agricultural Warehouses}

The warehouses were checked based on structural requirement, which consists of a number of variables, to evaluate whether they conform to the structural requirements mandated in the Philippine Agricultural Engineering Standards (PAES419:2015) and results were encapsulated in this study.

On the basis of the quantitative findings expounded in the preceding table, it can be observed that:

Item (i): Based on the findings, $89.47 \%$ of the warehouses followed the structural requirements outlined in the PAES 419:2015 with respect to the floor's elevation and $100 \%$ with respect to its safety. Code of Good Warehousing Practices (GWP) stated that the floors should be constructed sufficiently above ground level and free from cracks to avoid moisture accumulation from the ground which may affect and/or contaminate the stored grains.

Item (ii): Majority of the warehouses, $73.68 \%$ do not conform to the PAES in terms of the color of the warehouse. PAES 419:2015 states that the walls shall be painted white, on the inside to facilitate the detection of insect pests and on the outside to help keep the warehouse look as cool as possible and for sanitary purposes. The figures reflect that most of the warehouses do not meet the structural requirements of PAES in terms of walls. It is because most of the warehouses surveyed, uses its implementing agency's' trademark and as to what it embodies.

Item (iv): $94.74 \%$ of the surveyed warehouses followed the condition outlined in the Philippine Agricultural Engineering Standards in terms of roof.

Item (v): Only $10.53 \%$ and $47.37 \%$ of the visited warehouses do not conform to the requirements in
PAES stated under doors in terms of its wideness and if sliding or folding doors are fitted respectively. While $52.63 \%$ of the warehouses followed the PAES with the provision of canopy on every entry.

Item (vi): More than $50 \%$ of the population comply with the PAES with the provision of proper ventilation inside the warehouses. Code of Good Warehousing Practices (GWP) stated that ventilation systems shall be designed and constructed to provide proper aeration and to maintain the desired temperature.

\subsection{Functional Requirements of Agricultural Warehouse}

The warehouses were checked in which they consisted a number of variables, to evaluate whether they conform to the functional requirements stated in the Philippine Agricultural Engineering Standards (PAES. And the results are summarized as:

Item (i): Majority of the warehouses, $73.68 \%$ utilizes the Chinese Method on their system of piling. Not applicable indicates that the sample has non-functional warehouses.

Item (ii): More than half of the population, $57.89 \%$ followed the space requirement stated in PAES in terms of the stacking height and $63.16 \%$ in terms when sacks are made of polypropylene. While $26.32 \%$ falls into not applicable since it has non-functional warehouses.

Item (iii): Most of the warehouses followed the stated requirements in pathway and side spacing outlined in the PAES while $26.32 \%$ is not applicable.

Item (iv): Majority of the surveyed warehouses, $78.95 \%$ observed the proper storing of machines mentioned in the PAES while half of the population, $73.68 \%$ observed the machine's proper maintenance.

Item (v): $84.21 \%$ of the warehouses has properly trained operators and $57.89 \%$ conform to the provision of warehouse signage containing its name, code and location outside the warehouse. However, $78.95 \%$ of the warehouse do not have provision of first aid kit.

Item (vi): Most of the visited warehouses do not followed proper installation of fire equipment/exits inside the warehouse as stated in the PAES.

Item (vii): Majority of the surveyed warehouses, do not have all the facility requirement as required by the PAES. Facilities are vital in a warehouse to fully serve its service and accommodate all the produce in maintaining its quality and avoid losses. $\square \quad$ Item (viii): $84.21 \%$ of the responses from the warehouses exposes that the requirement stated in PAES in managing waste disposal was not followed. Waste disposal management is important to reduce the effect of waste in the environment. It is also important for public health. 


\section{Conclusions and Recommendations}

Based on the results of the data from survey, the analysis concluded the existing agricultural warehouses within the province are suitable to where it is located. Moreover, results in the evaluation of the technical profile in terms of structural requirements, most of the warehouses conforms to the Philippine Agricultural Engineering Standards (PAES). In addition, results in the evaluation of the technical profile in terms of functional requirements reveal that the existing agricultural warehouses do not followed all the outlined requirements in the PAES. Furthermore, the researcher would like to recommend (a) evaluating the existing agricultural warehouse's profile in terms of: management and operational processes and socioeconomic impact; and (b) assessing the level of demand and capacity of the existing agricultural warehouses.

\section{References}

[1] Aayam Exim. (n.d.). Warehouse. Retrieved from http://www.aayamexim.com/

[2] K. H., Adams (2007). Research Methods for Graduate Business \& Social Science Students. California, Sage.

[3]Agricultural Machinery Testing and Evaluation Center. (AMTEC). Philippine Agricultural 287 Engineering Standard (PAES) 419:2015, Agricultural Structures- Warehouse for Bag Type 288 Storage for Grains.

[4] Agricultural Marketing \& Agri-Business: Agro Processing: Storage and Warehousing. (2015). TNAU Agritech Portal. Retrieved from https://tinyurl.com/fz4mcrar

[5] Agricultural Science: Storage of Farm Produce. (2020, July 09). Seedak. Retrieved from https://tinyurl.com/2kbdpntb

[6] Andales, S.C. et al (2000). Priorities and Constraints of Post-harvest in the Philippines. Technical Reference Guide on Grains Post-harvest. BPRE. Muñoz, Nueva Ecija. Philippines, third edition, p.11. Retrieved from https://tinyurl.com/y5y9wsuk

[7] DA (2001). Unpublished Accomplishment Report. Department of Agriculture. Quezon City, Philippines.

[8] Description: Farm Product \& Warehousing Storage in the US. (2021, March). Market Research.com. Retrieved from https://tinyurl.com/3v526xjh

[9] Edwards, W. (2013). Grain Storage Alternatives: An Economic Comparison. Ag Decision Maker, Iowa State University of Science and Technology, Ames, Iowa. USA, pp. 1

[10] File: Ph fil agusan del sur.png. (2021, June 21). Wikimedia Commons, the free media repository. Retrieved 10:59, July 25, 2021 from https://tinyurl.com/8jcsuydm
[11]IndiaFreeNotes. (2020, August 27). University of Mumbai BMS Notes: Types of Warehouses Retrieved from https://tinyurl.com/x3k5k5ut

[12] Israel, G. D. (1992, October). Determining Sample Size. PEOD6, pp. 1-5.

[13] Machakova, J. (2009). Economic Evaluation of A Warehouse Investment in Central Europe: Case Study at Nokian Heavy Tyres Ltd. [Student Thesis, University of Applied Sciences]. Retrieved from https://tinyurl.com/3bwasjk6

[14] Philippine National Standards. Code of Good Warehousing Practices (GWP) for Grains

[15] Sanchez, P. D. C., Hashim, N., Shamsudin, R., \& Mohd Nor, M. Z. (2021). Effects of different storage temperatures on the quality and shelf life of Malaysian sweet potato (Ipomoea Batatas L.) varieties. Food Packaging and Shelf Life, 28, p. 1. https://doi.org/10.1016/j.fps

[16] Hussain, G., Bilal, M., Sultan, M, Miyazaki, T., Mahmood, M. H., Khan, Z. M. Investigating Applicability of Heat-Driven Desiccant Dehumidification System for Shelf Life Improvement of Fruits and Vegetables. Proceeding of International Exchange and Innovation Conference on Engineering \& Sciences (IEICES) 6 (2020). Interdisciplinary Graduate School of Engineering Sciences, Kyushu University

[17] Mortyas, S., Anggi, R., \& Ridwan, M. (2018). Adapting Buildings for Climate Change: Will Indonesian Traditional Houses Shift to Zero Energy Buildings? :

Proceedings of International Exchange and Innovation Conference on Engineering \& Sciences (IEICES). 4, pp.56-59, 2018-10-18. Interdisciplinary Graduate School of Engineering Sciences, Kyushu University. 